\title{
Application of Virtual Reality Technology in Distance Learning
}

\author{
https://doi.org/10.3991/ijet.v11i11.6257 \\ Xue-qin Chang, Dao-hua Zhang, Xin-xin Jin \\ Bozhou University Anhui, Anhui, China
}

\begin{abstract}
Virtual reality technology is a way for teachers and students to create a simulated three-dimensional world, a vivid and lifelike learning evironment for students in terms of vision, hearing and touch, having the students feel as participants of the virtual environment.A multi-user virtual campus system based on virtual reality technology is put forward in this paper, which includes the basic models, system structure and implementation scheme. The system is a simulation of real life in campus where students can take activities such as having class, doing exercises and making friends; and teacher can make lectures, review works of students and conduct examinations; managers can manage the daily teaching activities and students' affairs.
\end{abstract}

Index Terms - virtual reality, distance education, 3D

\section{INTRODUCTION}

Compared with that in the past, modern distance education shows the following new trends. Firstly, the vehicle for spreading knowledge is no longer radio or television but computer. Network is employed to achieve long distance interaction between teachers and students and realtime or non-real-time interactive learning. Teachers can give real-time instruction to students via video and BBS, so that students can take up the online study of "Elearning" via real-time communication and interaction with their teachers. And non-real-time instruction and learning can also be applied, such as courseware resources and offline assignments. Secondly, teaching resources have developed from the printed materials and audiovisual cassettes and videos of the traditional distance education to various forms such as VCD, DVD, courseware, network course, featured website, resource pool and question bank. Administrative and geographical restrictions on the content of teaching resources are lifted. The excellent educational resources nationwide and even abroad are integrated to provide students with the richest learning resources. Thirdly, the educated are no longer merely the students of distance education who aim at diplomas and degrees but all the population who wish to learn. With the development of network technology and the popularization of computers, this population can reach all walks of life including governmental institutions, businesses, the countryside and families[1-2]. The provision of rich educational resources anytime and anywhere facilitates the learning of those who wish to learn.

Fourthly, the simple long-term academic education is converted to the combination of academic education and short-term non-academic education such as further education and vocational training, for the purpose of developing knowledge and skills.

\section{New Problems With Distance EdUCATION MANAGEMENT}

Over recent years, the development of modern distance education has enabled more people to know about and recognize this form of education, meanwhile, the constant increase of enrollment size poses a series of problems[3].

(1) Poor human resources in distance education. Apart from the expertise, teachers of modern distance education frequently need to process their expertise technically to create online teaching resources for the use of more learners. But there are only a few full-time teachers in terms of traditional distance education, and the part-time teachers are generally experts from regular institutions of higher education. Due to the shortage of approaches and knowledge in distance education, these part-time teachers fail to present their specialty with the teaching resources, especially, many technical problems of distance education cannot be solved, which obviously indicates an insufficient communication between experts and technicians as well as the failure to create team synergy, thus impairing the quality of distance education.

(2) Quality reduction of the students receiving distance education. The development of distance education as well as its expansion in size leads to the weakening of management for traditional distance education which fails to serve a large number of learners distributed over different regions. The staff shortage in teaching management and educational administration, poor techniques and teamwork give rise to lagged management, low efficiency and constant reduction in educational quality, thus failing to satisfy the learners' desire for learning. It causes the instruction of distance education in many schools to turn out to be a mere formality and stifles students' initiative to learn, and the ineffective quality control measures bring about poor social feedback, therefore the reputation of distance education is tarnished.

(3) Heavy demand for investment in software and hardware of distance education, plus poor management. The hardware facilities of distance education include the network. Up to now, this network has been set up only in a few developed regions, and huge investment is needed for those underdeveloped regions. Both the constant improvement of software and the enhancement of the universality of network instruction software platform need considerable input of funds. The single instructional software of three-part-separated screen cannot suit the multiple requirements of students, so the network courseware which suits students' requirements needs to be developed. The root cause of the new problems with distance education lies in the shortage of scientific and standard management methods for modern distance education. Obvi- 


\section{SHORT PAPER \\ APPLICATION OF ViRTUAL REALITY TECHNOLOGY IN DiSTANCE LEARNING}

ously, the management methods for traditional distance education are not applicable with low efficiency and benefits as well as the lack of cost management and quality management. Therefore, scientific management methods need to be introduced into modern distance education.

\section{The Role OF Virtual REALITy TECHNOLOGY AND ITS APPLICATION IN DisTANCE EDUCATION}

The emergence of virtual reality technology and mature, not only to promote the popularization and application of virtual reality technology, and bring new teaching means for remote teaching. The virtual reality technology in the remote teaching is introduced as a new form of media, can the teaching scenario, the virtual teaching experiment, skill training, use of interactive virtual reality scene, immersion, more perceptual and operability advantages to express the teaching content, can solve the key and difficult point in teaching, fully mobilize students' learning initiative and creativity, promote the construction of students' knowledge system.

Virtual reality technology is the use of $3 \mathrm{~d}$ graphics generation technology, multiple sensing interactive technology and high resolution display technique, the simulation environment and simulation system, visual system three for one, the use of psychology, control science, computer graphics, physics, mathematics, and many other disciplines to generate $3 \mathrm{~d}$ realistic virtual environment, experience, as long as you wear a special helmet, data glove, such as sensors, or use of the keyboard, mouse, input devices, such as real-time interaction, to get into the virtual space perception and operation of various objects in the virtual world, in order to gain immersive feeling and experience.

\section{A. Knowledge learning}

Learning knowledge is the remote education students can make use of virtual reality system to learn all kinds of knowledge. Virtual reality technology applied on the one hand, learners are now real life could not be observed natural phenomenon or things change process, and can provide learners with vivid, lifelike perceptual learning environment and information, to help solve the difficulty and keystone of learning knowledge. For instance, in learning physics knowledge in the nuclear fission, the conductive principle of semiconductor, such as complex physical phenomena, use of virtual reality technology provides students observe the scene. On the other hand can be abstract concepts, theoretical visualizations and abstraction, deepen students' understanding of abstract concepts.

\section{B. The exploring learning}

Virtual reality technology can make use of virtual various hypothetical model, through the implementation of the virtual system to verify the result of a hypothesis model or effect. For example, using the virtual chemical experiment system, students will different molecules together, system can be virtual compound material. Through this exploratory study way, students are more likely to develop the new material, can stimulate students' creative thinking, cultivate the students' innovation ability.

\section{Virtual experiment}

Using virtual reality technology, also can build all kinds of virtual laboratory, such as physics, geography, chemis- try, biology, etc. In this lab, students are free to do all kinds of experiment. For example, in the virtual physics lab, students can do acceleration, inertia experiment; In the virtual geographic laboratory, volcanic eruptions, landslides, etc experiment; In the virtual chemical laboratory, can do a variety of chemical reaction, observed phenomenon of combustion, explosion and other reactions.

\section{Skills training}

Immersion of virtual reality and interactivity, allowing students to play a role in the virtual learning environment, devoting themselves to their learning environment, skill training. Such as medical students' surgical skills, students' teaching skills, vehicle driving skills, electrical maintenance, etc. Various vocational skills training. Due to the virtual reality technology training system didn't dangerous safer, students can practice and practice repeatedly, until the master operation skills.

\section{Multi-User Virtual Campus For Distance EDUCATION}

People involved in distance education include students in various locations, teachers who are in different location from students, managers who in charge of the system and other employees. They are different group people regarding to the requirement to the system. This paper engaged in establishing a system which will make distance education sustainable, cohesive and convenient for all users.

\section{A. Basic concept}

To make the virtual campus more convenient and economical, this paper combines the three dimensional scenery supplied by virtual reality technology and the information dissemination mode of traditional website, such as email, VOIP, camera chat etc together to establish a networked multi-users virtual campus which can realize the combination and share of the teaching resources which can be browsed and This virtual system experiment used freely, and benefit to the users and managers of the distance education system.

The WMUVC is environment established in $3 \mathrm{D}$ form which can afford a vivid image of the university and is more flexible than 2D rendering form. During the process of course taking, one student can communicate and discuss with teacher and other students as in real classroom, even, refer to experiment courses, students can observe the details and steps of the experiment conduct by teacher. $3 \mathrm{D}$ rendering form excels $2 \mathrm{D}$ form change of vision either in course vitality or reality, and is much fit for guiding students to study.

The system is a simulation of real life in campus for students can take actives such as having class, taking exercises and making friends; as well as in the real campus, teacher can lecture, review works from students, conduct examinations; managers can manage the daily teaching actives and students' affairs.

\section{B. System Architecture}

As the users have different level of knowledge about computer and internet, the WMUVC's structure should be simple and it should offer intuitive navigation which could make users communicate naturally. The navigation occurs through a virtual mockup that affords mobility and access to the services available. For remote access to the system and to its services, the interface of communication of the 
system uses a client-server structure. This way, the user can access a homepage to connect him to an application that establishes a connection with the server through internet.

Mockups in WMUVC are modeled and organized according to structural aspects in the real world and this organization reflects the relationship between mockups. The structural diagram of the system is shown as Fig.1, in which virtual classroom, laboratories and library are connected to each other. Users can access every virtual entity through the network after identity validation.

The system is composed by: a virtual mockup situated in a Client subsystem; an interface of communication, responsible for the access to the services; and a layer of applications available for users, situated in the Server subsystem. The Client subsystem is responsible for the management and sending requests for the Server through the Internet. The Server subsystem is responsible for translation, processing and reply of the requests.

The theoretical model of WMUVC is shown in Fig.2, which is comprised of three major parts. The left part and right part is the model of student subsystem and teacher subsystem, respectively, which comprise five layers, and the middle part is the Open System Interconnection (OSI) model which comprises seven layers. The left part and right part communicate and exchange information through the middle part. The five layers of WMUVC include:

1. Perception layer: this layer supplies the user with a virtual campus, and the user can interact with the virtual campus, teacher, and other classmates freely and naturally.

2. Function layer: this layer consists of the basic functions of WMUVC, including design of the system, simulation to the physical world, transferring information and displaying images and other information, etc.

3. Algorithm layer: this layer integrates the algorithms necessary for the operation of WMUVC system, such as planning algorithm, graphic rendering algorithm and data processing algorithm.

4. Information layer: this layer includes the information of campus, course and teacher description, demonstration of some experiments, displaying of the mockups and other things in WMUVC, etc.

5. Physical layer: this layer comprises the hardware of the virtual environment such as classrooms and other buildings, experimental instruments, tables, chairs, etc.

While the seven layers of OSI model include application layer, presentation layer, session layer, transport layer, network layer, data link layer, and physical layer. The dashed block is the established WMUVC system. Students can enter any virtual classroom to having class; any laboratory to operate experiments; library to reading books, teachers can lecture in the virtual classroom or laboratory, and managers can overview the activities and process occurring in the system, as long as their identities is validated.

\section{Communicate interface}

Considering variety of the users, the communicate interface of the system should be flexible, available and easy to use. As the C-S construction of the system, the interface

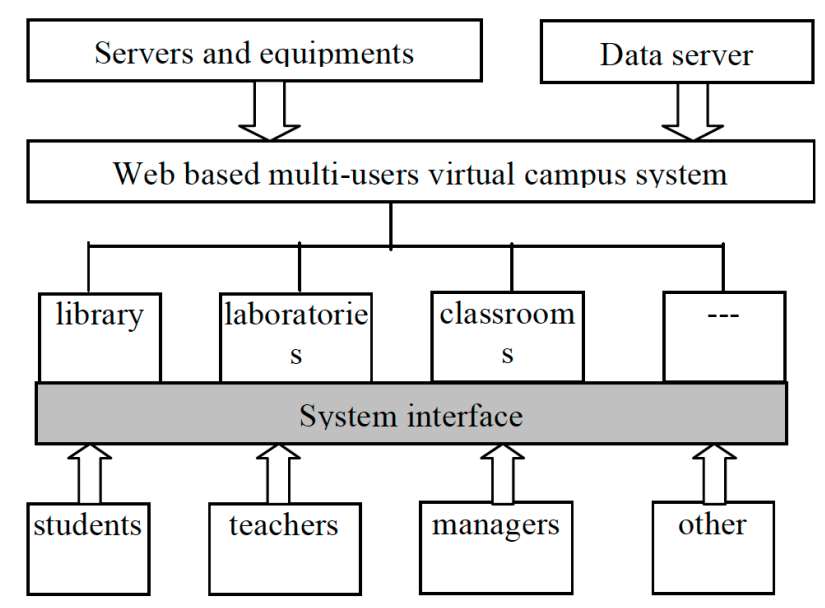

Figure 1. The structure of web based multi-users virtual campus system

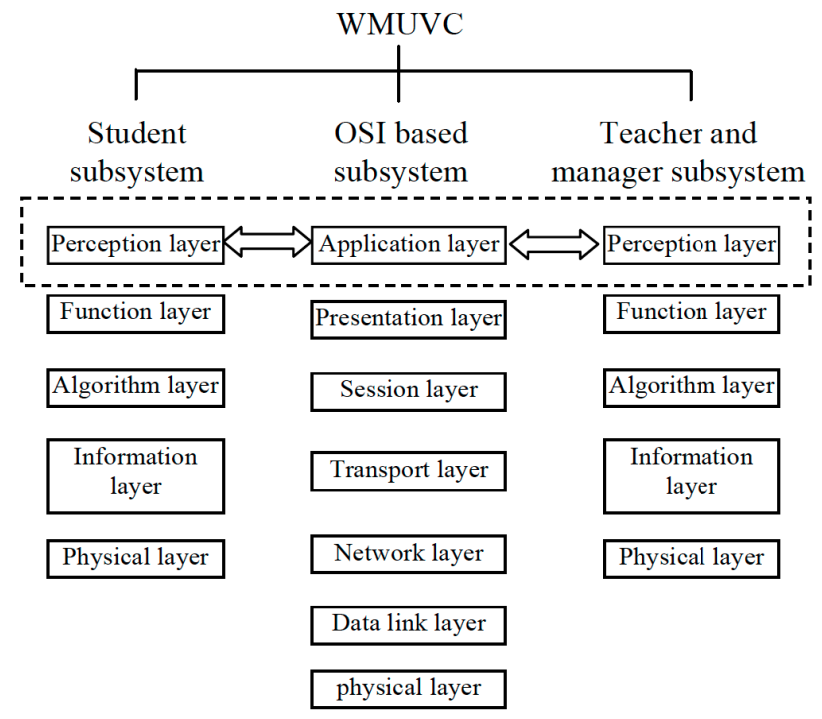

Figure 2. The theoretical model of WMUVC.

could built on the web browser such as Microsoft Internet Explorer, Firefox, Opera, Safari etc, then users can access the information and take courses anywhere, any time as long as they work with computer and internet.

Furthermore; the WIFI could be the solution to connect the users and system too, then, users can acquire the information and message with a smart phone, justly. This will make the system more convenient, and flexible.

\section{Data and security issues}

Expressing the special information of the users and non-spatial data of the objective world such as buildings teaching equipments in the virtual environment is an important goal and difficult task in WMUVC system. Since complexity and diversity of the real world, various data is essential and should be integrated, and a complex data model is used to express the system's vector data, raster data, as well as CAD data[4-5]. For the sake of management and collection, data are divided into spatial data and management data as shown in Table I.

Although one would expect relatively open access to a University campus, it would not be unreasonable to restrict access to some areas to either staff only or students and staff only, to prevent, for example, casual visitors from disrupting a teaching session. Virtual worlds as with 
TABLE I.

A LIST OF DATA TYPES

\begin{tabular}{|l|l|l|}
\hline \multicolumn{1}{|c|}{ Data name } & \multicolumn{1}{|c|}{ sources } & \multicolumn{1}{c|}{ functions } \\
\hline Topographic map & Maps of the real world & $\begin{array}{l}\text { To provide information for } \\
\text { simulation to the real world }\end{array}$ \\
\hline Buildings data & $\begin{array}{l}\text { Photogrammetric } \\
\text { survey }\end{array}$ & $\begin{array}{l}\text { To provide referring infor- } \\
\text { mation for modeling }\end{array}$ \\
\hline Features data & Questionnaire & $\begin{array}{l}\text { To provide relative user' } \\
\text { information }\end{array}$ \\
\hline CAD data & $\begin{array}{l}\text { Engineering design } \\
\text { profiles }\end{array}$ & $\begin{array}{l}\text { To provide information for } \\
\text { mockups modeling }\end{array}$ \\
\hline Texture images & $\begin{array}{l}\text { Picture from digital } \\
\text { camera }\end{array}$ & $\begin{array}{l}\text { To provide a realistic } \\
\text { images for mockups }\end{array}$ \\
\hline
\end{tabular}

any other internet activity have their share of disruptive, destructive users, who seek to disrupt or deface sites in a similar fashion to website defacement. Access controls, although not infallible, can be imposed at varying levels of granularity, from restricting access to the site to registered users to restricting access to a particular venue to a class list.

\section{CONCLUSION}

Virtual reality technology as a new kind of remote education media technology, with its powerful teaching advantages and potential, is bound to vigorously promote the informatization development process of distance education. Applying VR technology in remote education research is still in its infancy, combined with the Web $3 \mathrm{~d}$ technology itself is not mature and standard is not unified, and hinders its application in distance education. System based on virtual reality technology is a systematic project, need to be done in accordance with the method of system engineering design and implementation.

\section{REFERENCES}

[1] H. Jing, "Node deployment algorithm based on perception model of wireless sensor network," International Journal of Automation Technology,vol.9, no.3, pp. 210-215, April 2015. https://doi.org/10.20965/ijat.2015.p0210

[2] H. Jing, "Routing optimization algorithm based on nodes density and energy consumption of wireless sensor network," Journal of Computational Information Systems, vol. 11, no.14, pp. 50475054, July 2015.

[3] Néstor Mora, Santi Caballe, and Thanasis Daradoumis, "Providing a Multi-fold Assessment Framework to Virtualized Collaborative Learning in Support for Engineering Education," International Journal of Emerging Technologies in Learning, vol. 11, no.7, pp. 41-55, July 2016. $\quad$ https://doi.org/10.3991/ijet. v11i07.5882

[4] H. Jing, "The Study on the Impact of Data Storage from Accounting Information Processing Procedure," International Journal of Database Theory and Application, vol. 8, no.3, pp. 323-332, June 2015. https://doi.org/10.14257/ijdta.2015.8.3.28

[5] T. Yang, B. Yu, H. Wang, et al., "Cryptanalysis and improvement of Panda - public auditing for shared data in cloud and internet of things," Multimedia Tools and Applications, pp. 1-18, December 2015. https://doi.org/10.1007/s11042-015-3139-7

\section{AUTHORS}

Xue-qin Chang, Dao-hua Zhang, and Xin-xin Jin are with Bozhou University Anhui, Anhui, China (bzuni021@chinauniedu.com).

The paper is supported by The anhui province quality project of "flying snow" guest room (2015ckjh121), Bozhou university field horizontal topic: the mouse + cement marketing strategy research(BSHX1509). Submitted 09 September 2016. Published as resubmitted by the authors 30 October 2016. 